\title{
Titanium dioxide nanotubes addition to self-adhesive resin cement: Effect on physical and biological properties
}

\author{
Carla M. Ramos-Tonello ${ }^{a}$, Paulo N. Lisboa-Filho ${ }^{b}$, Larisa B. Arruda ${ }^{b}$, \\ Cintia K. Tokuhara ${ }^{c}$, Rodrigo C. Oliveira ${ }^{c}$, Adilson Y. Furuse ${ }^{a}$, \\ José H. Rubo ${ }^{d}$, Ana Flávia S. Borges ${ }^{a, *}$ \\ a Department of Dentistry, Endodontics and Dental Materials, Bauru School of Dentistry, University of São Paulo, \\ Bauru, SP, Brazil \\ ${ }^{\mathrm{b}}$ Department of Physics, Faculty of Science, State University of São Paulo, Bauru, SP, Brazil \\ c Department of Biological Sciences, Bauru School of Dentistry, University of São Paulo, Bauru, SP, Brazil \\ d Department of Prosthodontics, Bauru School of Dentistry, University of São Paulo, Bauru, SP, Brazil
}

\section{A R T I C L E I N F O}

Article history:

Received 31 January 2017

Received in revised form

10 April 2017

Accepted 28 April 2017

\section{Keywords:}

Dental cements

Polymerization

Nanotechnology

Nanotubes

Titanium

Physical and chemical properties

Mechanical phenomena

\begin{abstract}
A B S T R A C T
Objectives. This study has investigated the influence of Titanium dioxide nanotubes $\left(\mathrm{TiO}_{2}\right.$ nt) addition to self-adhesive resin cement on the degree of conversion, water sorption, and water solubility, mechanical and biological properties.

Methods. A commercially available auto-adhesive resin cement (RelyX U200 ${ }^{\mathrm{TM}}$, 3M ESPE) was reinforced with varying amounts of nanotubes $(0.3,0.6,0.9 \mathrm{wt} \%)$ and evaluated at different curing modes (self- and dual cure). The DC in different times (3, 6, 9, 12 and $15 \mathrm{~min}$ ), water sorption (Ws) and solubility (Sl), 3-point flexural strength ( $\sigma f)$, elastic modulus (E), Knoop microhardness $(\mathrm{H})$ and viability of $\mathrm{NIH} / 3 \mathrm{~T} 3$ fibroblasts were performed to characterize the resin cement.

Results. Reinforced self-adhesive resin cement, regardless of concentration, increased the $\mathrm{DC}$ for the self- and dual-curing modes at all times studied. The concentration of the $\mathrm{TiO}_{2}$ nt and the curing mode did not influence the Ws and Sl. Regarding $\sigma f$, concentrations of both 0.3 and $0.9 \mathrm{wt} \%$ for self-curing mode resulted in data similar to that of dual-curing unreinforced cement. The $\mathrm{E}$ increased with the addition of $0.9 \mathrm{wt} \%$ for self-cure mode and $\mathrm{H}$ increased with 0.6 and $0.9 \mathrm{wt} \%$ for both curing modes. Cytotoxicity assays revealed that reinforced cements were biocompatible.

Significance. $\mathrm{TiO}_{2}$-nt reinforced self-adhesive resin cement are promising materials for use in indirect dental restorations. Taken together, self-adhesive resin cement reinforced with $\mathrm{TiO}_{2}$-nt exhibited physicochemical and mechanical properties superior to those of unreinforced cements, without compromising their cellular viability.
\end{abstract}

@ 2017 The Academy of Dental Materials. Published by Elsevier Ltd. All rights reserved.

\footnotetext{
* Corresponding author at: Bauru School of Dentistry, University of São Paulo, Al. Octávio Pinheiro Brisola, 9-75, Vila Universitária, 17012-901 Bauru, SP, Brazil.

E-mail address: afborges@fob.usp.br (A.F.S. Borges).

http://dx.doi.org/10.1016/j.dental.2017.04.022

0109-5641/@ 2017 The Academy of Dental Materials. Published by Elsevier Ltd. All rights reserved.
} 


\section{Introduction}

Self-adhesive resin cements were developed to clinical time by simplifying cementation procedures due to the elimination of the acid etching and application of adhesive steps [1-3]. Its adhesive properties are attributed to the presence of the modified acidic group's methacrylate monomers that allows the infiltration and demineralization of the substrate, that result in micromechanical retention and chemical bonding with hydroxyapatite [3]

However, the presence of these acidic monomers in selfadhesive resin cements may adversely affect the degree of conversion (DC) because of its interference with the amine coinitiator, which results in changes in the curing [4] and the loss of some physical and mechanical properties [5-7]. Moreover, being dual-cured, not all cements present the same conversion rates of monomers when self- or/and light-activated. In general, light-activation promotes higher conversion of monomers [8].

To improve certain properties of resin materials, the addition of titanium dioxide nanostructures have demonstrated positive results in the behavior of polymeric materials such as resin composites [9,10], flowable resin composites [11], orthodontic resin cements [12] and glass ionomer cements [13]. The decrease in size of different oxides at the nanoscale promotes a wide range of applications in different materials because their behavior changes when compared to the bulk size [14], making it an effective functional material [15]. Nanosized oxides such as $\mathrm{TiO}_{2}$ can provide unique physical and chemical properties due to their small size and high density of surface sites, increasing their reactivity and interaction with the environment [16]. In particular, the nanotubes' shape provides a large surface area that can give rise to strong internal and external interactions with the matrix in which they are embedded, chemical stability and a high refractive index [17].

Whereas oxides at the nanoscale can be easily incorporated into the resin-based materials when manipulated, adding these to the self-adhesive resin cement can be an alternative to improve the overall performance of the indirect restoration. Therefore, the aim of the current investigation was to determine the physical-chemical, mechanical and biological properties of a self-adhesive resin cement (RelyX $\mathrm{U} 200^{\mathrm{TM}}$-Seefeld, Germany) in the presence of $\mathrm{TiO}_{2}$-nt at three different concentrations: $0.3 \%, 0.6 \%$ and $0.9 \%(\mathrm{w} / \mathrm{w})$.

\section{Materials and methods}

\subsection{Experimental design}

The factor under study was the incorporation of different concentrations of $\mathrm{TiO}_{2}$-nt (w/w) into self-adhesive resin cement RelyX U200 ${ }^{\mathrm{TM}}$. For degree of conversion (DC), the study factors were as follows: (1) concentration of $\mathrm{TiO}_{2}$-nt $(0.3,0.6$ and 0.9 wt.\%), (2) curing mode dual- and self-curing and (3) time (3, $6,9,12$ and $15 \mathrm{~min}$ ). For water sorption (WS) and solubility (SL), flexural strength $(\sigma f)$, modulus of elasticity $(E)$ and hardness $(\mathrm{H})$, the study factors were: (1) concentration of $\mathrm{TiO}_{2}$-nt $(0.3$, 0.6 and $0.9 \mathrm{wt} \%$ ) and (2) curing mode (dual- and self-curing).
For cell viability study, the factors were as follows: (1) concentration of $\mathrm{TiO}_{2}$-nt $(0.3,0.6$ and $0.9 \mathrm{wt} . \%)$ and (2) time (24, 48 and $72 \mathrm{~h}$ ). Two polymerization conditions were used: selfand dual-cured polymerization. For the self-curing condition, the cement handling and the specimens' preparation were performed in an environment with room light. Thirty minutes after cement handling, specimens were removed from the custom devices used in each test and stored in distilled water at $37^{\circ} \mathrm{C}$. For the dual-curing condition, the specimens were handled in an environment with room light, embedded in custom devices used in each test of the study. Nine minutes after handling of self-adhesive resin cement, the light source $780 \mathrm{~mW} / \mathrm{cm}^{3}$ DB LED 686 (Dabi Atlante, Ribeirão Preto, Brazil) was applied for $20 \mathrm{~s}$ in different areas of the specimens so that the whole specimen was reached by light. The $9 \mathrm{~min}$ time was used once delay in light activation had shown to improve properties of resin-based cements [18,19].

The specimens of the self-adhesive resin cement were randomly assigned into 8 groups: SCT = self-adhesive resin cement in self-cure condition, which has no $\mathrm{TiO}_{2}$-nt; S03 = self-adhesive resin cement in self-cure condition with the addition of $0.3 \mathrm{wt}$. $\%$ of $\mathrm{TiO}_{2}$-nt; $\mathrm{S06}=$ self-adhesive resin cement in self-cure condition with the addition of $0.6 \mathrm{wt} . \%$ of $\mathrm{TiO}_{2}$-nt; $\mathbf{S 0 9}=$ self-adhesive resin cement in self-cure condition with the addition of 0.9 wt. $\%$ of $\mathrm{TiO}_{2}-\mathrm{nt}$; DCT $=$ selfadhesive resin cement in dual-cure condition, which has no $\mathrm{TiO}_{2}$-nt; $\mathrm{D} 03$ = self-adhesive resin cement in dual-cure condition with the addition of 0.3 wt.\% of $\mathrm{TiO}_{2}-\mathrm{nt}$, dual cure; D06 = self-adhesive resin cement in dual-cure condition with the addition of $0.6 \mathrm{wt}$. $\%$ of $\mathrm{TiO}_{2}$-nt; $\mathrm{D} 09=$ self-adhesive resin cement in dual-cure condition with the addition of $0.9 \mathrm{wt} . \%$ of $\mathrm{TiO}_{2}$-nt.

\subsection{Specimen preparation}

$\mathrm{TiO}_{2}$-nt were obtained from a commercial mixture of anatase $\mathrm{TiO}_{2}$ powder (Sigma-Aldrich, St. Louis, USA) mixed with an alkaline solution of sodium hydroxide $(\mathrm{NaOH} ; 10 \mathrm{M})$, which remained for $24 \mathrm{~h}$ at $120^{\circ} \mathrm{C}$ in an atmospheric pressure environment Teflon container. Then, the mixture was washed with deionized water and hydrochloric acid ( $\mathrm{HCl} ; 0.1 \mathrm{M})$ sequentially and repeatedly until reaching a $\mathrm{pH}$ of 4 . After that, the mixture were placed in a furnace at $200^{\circ} \mathrm{C}$ for $24 \mathrm{~h}$ to eliminate the liquid phase and to obtain the final powdered material [20]. The nanotubes were measured with open source Image J software and had an average diameter of $10 \mathrm{~nm}$ and were $200 \mathrm{~nm}$ in length, formed by a single sheet of spiral-wound $\mathrm{TiO}_{2}$. The image was obtained by Transmission Electron Microscopy (TEM) (CM 200, Phillps, Netherlands) with electrons acceleration of $200 \mathrm{kV}$ [20]. The resin cement that had the same portion of base and catalyst paste dispensed by packing clicker was dispensed on a mixing pad and weighed on a precision scale of $0.0001 \mathrm{~g}$ (Denver Instrument, São Paulo, Brazil). Then, the nanotubes were weighed with the value corresponding to the resin cement weigh. $\mathrm{TiO}_{2}$-nt was manually added to the base paste and handled for $10 \mathrm{~s}$. Then, the base paste and $\mathrm{TiO}_{2}$-nt were mixed with the catalyst paste for another $10 \mathrm{~s}$. 


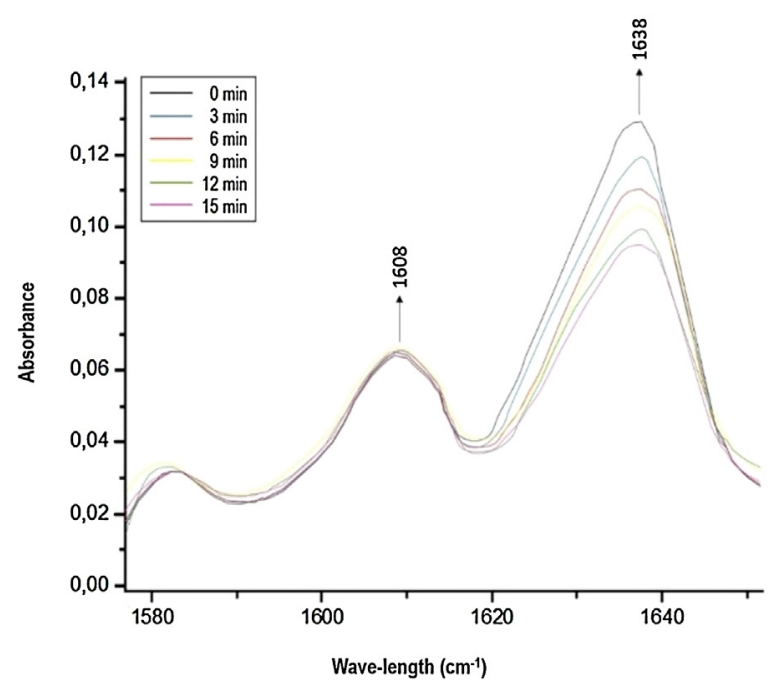

Fig. 1 - Peaks at 1608 and $1638 \mathrm{~cm}^{-1}$ identified in the spectral bands used for calculating the degree of conversion before polymerization $(0 \mathrm{~min}$ ) and after mixing base and catalyst pastes $(3,6,9,12$ and $15 \mathrm{~min})$.

\subsection{Degree of conversion}

The DC was evaluated by Fourier transformed infrared spectroscopy (IRPrestige-21, Shimadzu, Tokyo, Japan). The analysis was performed in reflectance mode using the attenuated total reflectance (ATR) accessory (MIRacle, Pike Technologies, Madison, USA). Cement specimens $(n=3)$ were analyzed at $0,3,6$, 9, 12 and $15 \mathrm{~min}$ after mixing base and catalyst pastes under self- and dual-cure polymerization conditions. After mixing the pastes and adding or not the nanotubes, small portions were placed covering the ATR crystal and the initial FT-IR spectra was obtained. For the self-cured groups, the resin cements were kept undisturbed and protected from light. For dualcured groups, the light source $780 \mathrm{~mW} / \mathrm{cm}^{3}$ was applied for $20 \mathrm{~s}$ on self-adhesive resin cement $9 \mathrm{~min}$ after the application on ATR crystal. The infrared spectrum of the specimen was obtained in the range of $1560-1760 \mathrm{~cm}^{-1}$ with 10 scans and consecutive resolution of $4 \mathrm{~cm}^{-1}$. Spectral bands were obtained, and the peak wavelength of aliphatic $1638 \mathrm{~cm}^{-1}$ (functional groups $\mathrm{C}=\mathrm{C}$ ) and aromatic $1608 \mathrm{~cm}^{-1}$ was identified for each time studied (Fig. 1). The DC was calculated using the equation:

$\mathrm{DC}(\%)=100 \times\left[1-\left(\mathrm{R}_{\mathrm{Tmin}} / \mathrm{R}_{0 \min }\right)\right]$

where $R$ is the ratio of the absorbance at $1638 \mathrm{~cm}^{-1}$ and absorbance $1608 \mathrm{~cm}^{-1}$ within the time determined for each record of the analysis (represented by $\mathrm{T}$ in the equation).

\subsection{Sorption (WS) and solubility (SL)}

For WS and SL, specimens were prepared $(n=8)$ for each of the 8 groups using a metallic mold with a cylindrical shape of $10 \mathrm{~mm}$ in diameter and 1-mm-thick. The method used was based on the ISO 4049 [21]. The specimens were kept in dry and dark storage for $24 \mathrm{~h}$, and then transferred to a desicca- tor at $37 \pm 1{ }^{\circ} \mathrm{C}$. After $22 \mathrm{~h}$ in the first desiccator, the specimens were removed, stored in a second desiccator at $25 \pm 1^{\circ} \mathrm{C}$ for $2 \mathrm{~h}$, and then weighed, using a 0.0001 precision analytical balance (Denver Instrument, Sao Paulo, Brazil) until a constant weight for each specimen (m1) was obtained (with no more than a $\pm 0.0001 \mathrm{~g}$ variation). The specimens were then immersed in deionized water at $37^{\circ} \mathrm{C}$. At fixed intervals, the specimens were removed from the water, blot-dried (in sequence using two absorbent papers) and weighed until a constant mass (m2) was obtained. The specimens were then stored in a desiccator in the presence of silica at $37^{\circ} \mathrm{C}$ and weighed until a constant weight (m3) was obtained, following the cycle described above for $\mathrm{m} 1$. The values for WS and SL (in $\mu \mathrm{g} / \mathrm{mm}^{3}$ ) were calculated using the following equations:

$\mathrm{WS}=\left(\mathrm{m}_{2}-\mathrm{m}_{3}\right) / \mathrm{V}$

$\mathrm{SL}=\left(\mathrm{m}_{1}-\mathrm{m}_{3}\right) / \mathrm{V}$

where $m_{1}$ is the specimen weight before immersion, $m_{2}$ is the specimen weight after immersion, $\mathrm{m}_{3}$ is the specimen weight after immersion and desiccation, and V is the volume of the specimen.

\subsection{Mechanical properties}

2.5.1. Flexural strength ( $\sigma f)$ and elastic modulus (E)

Resin cement bars $(n=10)$ were made for each group according to the polymerization conditions and addition of $\mathrm{TiO}_{2}$-nt. After mixing, the resin cement was inserted in a stainless steel mold for standardizing specimens dimensions $(2 \times 2 \times 25 \mathrm{~mm})$, as per ISO 9917-2 [22]. The specimens remained in distilled water at $37^{\circ} \mathrm{C}$ for $24 \mathrm{~h}$ before testing. The $\sigma f$ at three points was determined using a universal testing machine (Instron, Barueri, Brazil) with load-cell connected $50 \mathrm{~N}$ and a crosshead speed of $0.5 \mathrm{~mm} / \mathrm{min}$. The dimensions of the specimens were previously measured with a digital caliper (Starrett, Itu, São Paulo, Brazil). To perform the 3-point $\sigma f$, the specimens were placed on the device with a distance of $12 \mathrm{~mm}$ between the lower cylindrical support and the load applied to the center of the upper metal rod. Flexural-strength values were determined according to the equation:

$\sigma f=3 P L /\left(2 w b^{2}\right)$

where $\mathrm{P}$ is fracture load, $(\mathrm{N}) \mathrm{L}$ is the distance between the supports $(12 \mathrm{~mm}), \mathrm{w}$ is the specimen width $(\mathrm{mm})$ and $\mathrm{b}$ is the thickness (mm).

\subsubsection{Surface microhardness}

Microhardness measurements were obtained from 48 discshaped specimens $(10 \times 2 \mathrm{~mm} ; \mathrm{n}=6)$ on the surface using a microhardness instrument (Buehler, Lake Bluff, USA) with a Knoop diamond under a $50 \mathrm{~g}$ load for $10 \mathrm{~s}$. Before the measurements, the surface of specimens was polished with 600 , 800 and 1200-grit SiC (Extec CORP., Enfield, CT, USA, \#1060-524) papers for $2 \mathrm{~min}$ each, respectively. The measurement of the indentation was performed immediately after the period of $10 \mathrm{~s}$. Five indentations spaced $0.5 \mathrm{~mm}$ from each other were 
made in the central area of each specimen, and the arithmetical average was used for subsequent statistical analysis.

\subsection{Biological analyses}

\subsubsection{Preparation of specimens}

Four disks $(10 \mathrm{~mm} \varnothing \times 2 \mathrm{~mm})$ of resin cement were prepared for each concentration-studied $\mathrm{TiO}_{2}$-nt. After light curing, the specimens were autoclaved separately. To evaluate cell viability $(\mathrm{n}=8)$, an MTT (3-(4,5-dimethylthiazol-2-yl)-2,5diphenyltetrazolium bromide) assay was performed using only the dual-curing condition. The studied groups were DCT, D03, D06, D09, positive control (CP) and negative control (CN).

\subsubsection{Cell culture}

For cell culture, mouse fibroblasts were used in the NIH3T3 line P13 (ATCC $^{\circledR}$, Manassas, USA). The cells were cultured in DMEM-Dulbecco's modified Eagle (Aldrich ${ }^{\circledR}$ Sigma, St. Louis, USA), supplemented with $1 \%$ antibiotics (penicillin/streptomycin from Gibco ${ }^{\circledR}$, Waltham, USA) and 10\% FBS (fetal bovine serum from Gibco $^{\circledR}$ ) and remained incubated at $37^{\circ} \mathrm{C}$ with $5 \%$ carbon dioxide $\left(\mathrm{CO}_{2}\right)$. After reaching a subconfluence stage, a subculture was formed using the trypsin enzyme responsible for dissociating the culture bottle cells (0.25\% trypsin, $1 \mathrm{mM}$ EDTA from Sigma-Aldrich $\left.{ }^{\circledR}\right)$. After $5 \mathrm{~min}$ in an oven at $37^{\circ} \mathrm{C}$ with $5 \%\left(\mathrm{CO}_{2}\right)$, the trypsin was inactivated with DMEM culture medium with $10 \%$ FCS. The cells were transferred to a 50-ml falcon tube (Corning, NY, USA) and centrifuged at $1200 \mathrm{rpm}$ for $5 \mathrm{~min}$ at $20^{\circ} \mathrm{C}$. After centrifugation, the supernatant was discarded, and the cells were suspended again in a fresh DMEM medium with $10 \%$ FCS. After that, the cell count was performed using a trypan blue protocol optical microscope (Olympus, Japan). This dye is responsible for staining the viable cells as it penetrates the dead cells because their membranes can no longer eliminate it. Subsequently, the cells were plated in 96-well microplates (TPP ${ }^{\circledR}$, Trasadingen, Switzerland) for a colorimetric assay, 8-well microplates for each group. The resin-cement specimens were placed in contact with the culture medium following the recommendations of ISO 10993-5 [23] $\left(1 \mathrm{~cm}^{2} / \mathrm{ml}\right)$. To this end, the total area of the disks was calculated $\left(28.26 \mathrm{~cm}^{2}\right)$ to evaluate the amount of conditioned media $(28.26 \mathrm{ml})$. The specimens remained in the oven at $37^{\circ} \mathrm{C}$ for $24 \mathrm{~h}$. After this, the $\mathrm{pH}$ at which the disks were immersed was measured. For the viability assays, cells were plated $2 \times 103 /$ well in 96 -well plates $\left(\mathrm{TPP}^{\circledR}\right)$. After the enrollment period of $24 \mathrm{~h}$, the culture medium was replaced by DMEM 10\% FCS conditioned with the cement specimens. Each plate was examined at an experimental time of 24,48 and $72 \mathrm{~h}$ after the addition of conditioned medium. After each experimental period, the culture medium was removed, the cells were washed with phosphate buffered saline solution (PBS) and then an MTT reduction test.

\subsubsection{Analysis of cell metabolism MTT assay}

During each experimental period (24, 48 and $72 \mathrm{~h}$ ), the cells were washed with PBS and then incubated in $0.5 \mathrm{mg} / \mathrm{ml}$ solution (MTT/DMEM) for an MTT assay. This solution was prepared at the time of use and filtered through a Millipore filter $(0.22 \mathrm{mM})$ before being added to the plates. After this procedure, the plates remained in the greenhouse for $4 \mathrm{~h}$ at $37^{\circ} \mathrm{C}$ and $5 \% \mathrm{CO}_{2}$; then, the solution was removed, and the insoluble pigment reduced intracellularly was taken up in dimethylsulfoxide and left at room temperature for $30 \mathrm{~min}$. The absorbance was measured at $562 \mathrm{~nm}$ wavelength reader (Synergy H1 monochromator-based, Biotek, Winooski, USA).

\subsection{Statistical analyses}

Data were analyzed using the Shapiro-Wilk normality test. The DC data were subjected to ANOVA with repeatedmeasures followed by Tukey's HSD $(\alpha=0.05)$. WS, SL and each mechanical and biological property were submitted to twoway ANOVA and Tukey's HSD $(\alpha=0.05)$.

\section{Results}

\subsection{Degree of conversion}

The mean values and standard deviations are detailed in Table 1.

There were significant differences between curing mode $(p=0.000)$ and addition of nanotubes $(p=0.0000)$. The interaction was also found to be significant $(p=0.0000)$. The DC increases with time $(p=0.0000)$. The addition of $\mathrm{TiO}_{2}$ $n t$, regardless of concentration, increased the DC values for both self- and dual-curing conditions at all times studied. The DC analysis at $3 \mathrm{~min}$ showed that the addition of $0.3 \%(\mathrm{~S} 03=26.76 \% ; \mathrm{D} 03=26.11 \%)$ and $0.9 \%$ (S09=25.62\%; $\mathrm{D} 09=26.05 \%$ ) of $\mathrm{TiO}_{2}$-nt in the self-adhesive resin cement in both polymerization conditions showed the highest val-

\begin{tabular}{|c|c|c|c|c|c|}
\hline \multirow[t]{2}{*}{ Groups } & \multicolumn{5}{|l|}{ Time } \\
\hline & $3 \mathrm{~min}$ & $6 \min$ & $9 \min$ & $12 \min$ & $15 \mathrm{~min}$ \\
\hline SCT & $3.10 \pm 0.15^{\mathrm{a}}$ & $7.70 \pm 0.312^{b}$ & $14.62 \pm 0.20^{c}$ & $25.89 \pm 0.64^{e . f}$ & $28.38 \pm 0.45 \mathrm{~g} \cdot \mathrm{h}$ \\
\hline S03 & $26.76 \pm 0.29^{f . g}$ & $34.63 \pm 0.38^{j . k}$ & $41.03 \pm 0.18^{\text {n.o.p }}$ & $45.68 \pm 0.24^{\text {s.t }}$ & $45.76 \pm 0.25^{s . t}$ \\
\hline S06 & $24.36 \pm 0.20^{\mathrm{d}}$ & $30.75 \pm 0.26^{\mathrm{i}}$ & $35.40 \pm 0.51^{k}$ & $39.68 \pm 0.4^{\text {m.n.o }}$ & $40.51 \pm 0.33^{\text {n.o }}$ \\
\hline S09 & $25.62 \pm 0.30^{e . f}$ & $40.46 \pm 0.21^{\text {n.o.p }}$ & $42.15 \pm 0.58^{q . r}$ & $45.47 \pm 0.16^{\text {s.t }}$ & $46.51 \pm 0.17^{\text {s.t }}$ \\
\hline DCT & $3.09 \pm 0.54^{\mathrm{a}}$ & $7.94 \pm 0.15^{b}$ & $28.51 \pm 0.96^{g . h}$ & $37.39 \pm 0.49^{1}$ & $41.22 \pm 0.68^{\text {o.p }}$ \\
\hline D03 & $26.11 \pm 0.12^{f}$ & $33.97 \pm 0.36^{i . j}$ & $46.30 \pm 0.44^{\text {s.t }}$ & $47.20 \pm 0.17^{\text {t.u }}$ & $48.09 \pm 0.12^{\mathrm{u}}$ \\
\hline D06 & $24.13 \pm 0.18^{\text {d.e }}$ & $29.76 \pm 0.45^{h . i}$ & $38.36 \pm 0.54^{1 . m}$ & $39.70 \pm 0.43^{\text {m.n.o }}$ & $45.77 \pm 0.29^{\text {s.t }}$ \\
\hline D09 & $26.05 \pm 0.22^{f}$ & $39.89 \pm 0.16^{m \cdot n}$ & $44.12 \pm 0.38^{p . q}$ & $44.58 \pm 0.35^{\mathrm{r.s}}$ & $45.51 \pm 0.18^{\text {s.t }}$ \\
\hline
\end{tabular}


Table 2 - Average of the sorption (WS) and solubility (SL) values ( $\mathrm{mg} / \mathrm{mm}^{3}$ ). Within a row, values denoted by similar

superscript letters are not significantly different $(p>0.05)$.

\begin{tabular}{|c|c|c|c|c|c|c|c|c|}
\hline & \multicolumn{8}{|c|}{ Groups } \\
\hline & SCT & S03 & S06 & S09 & DCT & D03 & D06 & D09 \\
\hline $\mathrm{WS}\left(\mathrm{mg} / \mathrm{mm}^{3}\right)$ & $36.19^{a}$ & $36.25^{\mathrm{a}}$ & $37.15^{\mathrm{a}}$ & $37.25^{\mathrm{a}}$ & $37.47^{a}$ & $38.35^{\mathrm{a}}$ & $38.45^{\mathrm{a}}$ & $38.47^{\mathrm{a}}$ \\
\hline $\mathrm{SD}$ & 4.1 & 4.6 & 4.6 & 4.7 & 3.9 & 2.9 & 3.9 & 4.4 \\
\hline $\mathrm{SL}\left(\mathrm{mg} / \mathrm{mm}^{3}\right)$ & $7.66^{\mathrm{a}}$ & $7.77^{\mathrm{a}}$ & $7.98^{\mathrm{a}}$ & $8.00^{\mathrm{a}}$ & $8.01^{\mathrm{a}}$ & $8.05^{\mathrm{a}}$ & $8.12^{\mathrm{a}}$ & $8.14^{\mathrm{a}}$ \\
\hline $\mathrm{SD}$ & 1.8 & 1.9 & 2.2 & 2.3 & 2.0 & 2.0 & 1.9 & 2.4 \\
\hline
\end{tabular}

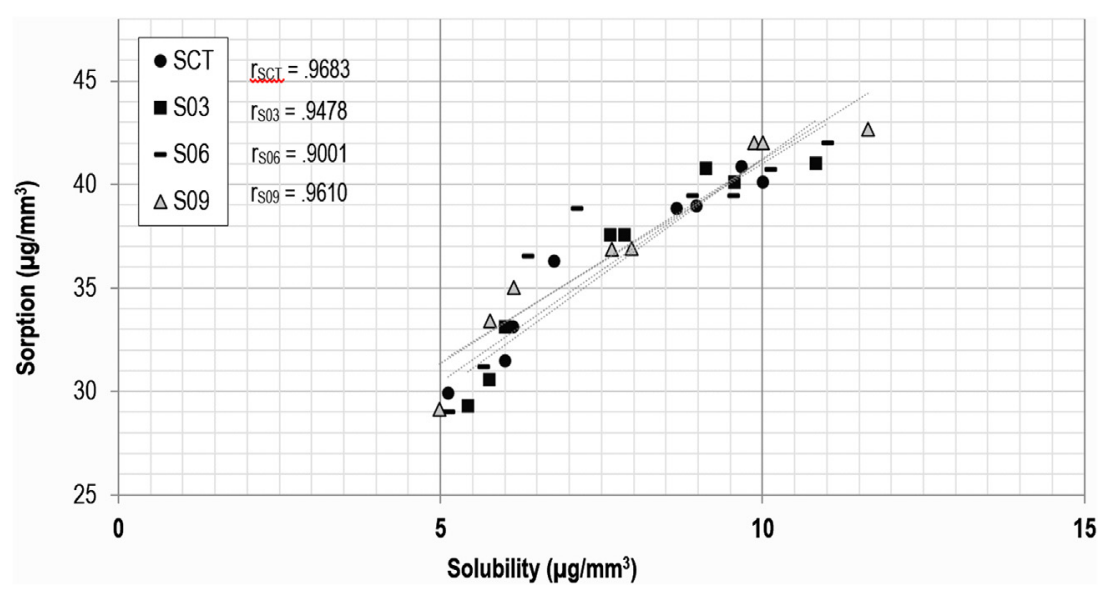

Fig. 2 - Correlation between WS and SL for the self-curing mode.

ues, similar to the SCT group at $12 \mathrm{~min}$ (SCT $=25.89 \%$ ). At $6 \mathrm{~min}$, an addition of $0.9 \% \mathrm{TiO}_{2}$-nt ( $\mathrm{S} 09=40.46 \%$; $\left.\mathrm{D} 09=39.89 \%\right)$ showed higher results when compared to other groups. The DCT control group showed an increase in the DC at a mean time of $9 \mathrm{~min}(28.51 \%)$ compared to the SCT group (14.62\%) that received no light. Regardless of the $\mathrm{TiO}_{2}$-nt concentration added, S03, S06 and S09 showed higher values than the DCT group at 9 and $12 \mathrm{~min}$. At $15 \mathrm{~min}$, only $\mathrm{S} 06$ group was similar to the DCT group. At $15 \mathrm{~min}$, the best result was found in the D03 group (48.09\%), with statistical differences for S09 (46.51\%). S03 (45.76\%), D06 (45.77\%) and D09 (45.51\%) had no difference between each other. The SCT group showed the lowest DC.

\subsection{WS and SL}

There was no significant difference between groups regardless the concentration of nanotubes added and polymerization condition ( $p>0.05)$. The mean values and standard deviations for WS and SL can be observed in Table 2. After a Pearson correlation analysis, an $80 \%$ correlation $(r>0.800)$ was observed between WS and SL in all groups studied regardless of the polymerization condition. Figs. 2 and 3 show the direct relationship between the WS and SL of each group for the selfand dual-curing conditions, respectively.

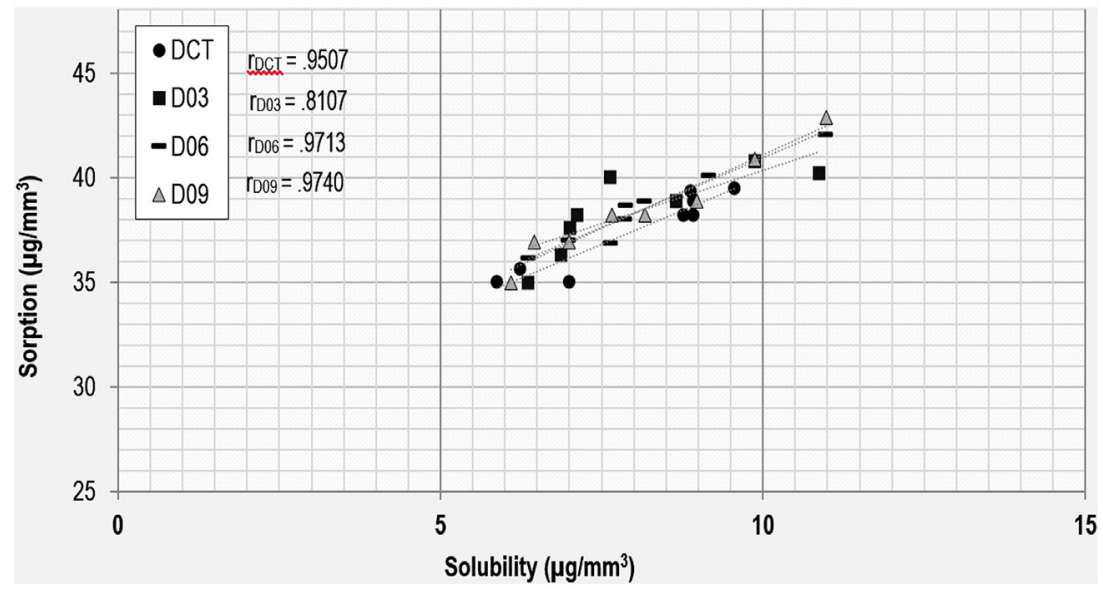

Fig. 3 - Correlation between WS and SL for the dual-curing mode. 
Table 3 - Mean values and standard deviation (SD) of flexural strength ( $\sigma \mathrm{f}$ ), elastic modulus (E) and Microhardness (H) for each group. Within a row, values denoted by similar superscript letters are not significantly different $(p>0.05)$.

\begin{tabular}{|c|c|c|c|c|c|c|c|c|}
\hline & \multicolumn{8}{|c|}{ Groups } \\
\hline & SCT & S03 & S06 & S09 & DCT & D03 & D06 & D09 \\
\hline$\sigma f(\mathrm{MPa})$ & $35.40^{c}$ & $59.40^{a . b}$ & $41.68^{c . d}$ & $55.22^{\text {a.b.c }}$ & $70.72^{b}$ & $57.61^{a . b}$ & $44.71^{\text {a.c.d }}$ & $58.43^{a . b}$ \\
\hline $\mathrm{SD}$ & \pm 10.41 & \pm 12.17 & \pm 16.03 & \pm 10.19 & \pm 12.18 & \pm 11.59 & \pm 7.19 & \pm 8.21 \\
\hline$E(\mathrm{GPa})$ & $1.01^{\mathrm{c}}$ & $1.27^{b . c}$ & $1.00^{c}$ & $1.71^{\mathrm{a} \cdot \mathrm{b}}$ & $2.22^{\mathrm{a}}$ & $1.76^{a \cdot b}$ & $1.67^{a . b}$ & $2.27^{\mathrm{a}}$ \\
\hline $\mathrm{SD}$ & \pm 0.31 & \pm 0.43 & \pm 0.34 & \pm 0.52 & \pm 0.56 & \pm 0.22 & \pm 0.52 & \pm 0.37 \\
\hline $\mathrm{H}$ & $58.18^{b}$ & $59.59^{a, b}$ & $60.35^{a}$ & $60.72^{a}$ & $58.20^{b}$ & $58.92^{a, b}$ & $60.05^{a}$ & $60.93^{a}$ \\
\hline SD & \pm 1.05 & \pm 2.63 & \pm 1.97 & \pm 1.61 & \pm 0.64 & \pm 1.53 & \pm 1.71 & \pm 1.16 \\
\hline
\end{tabular}

3.3. Flexural strength ( $\sigma f)$, elastic modulus $(E)$ and microhardness $(\mathrm{H})$

The mean values and standard deviations are detailed in Table 3. For $\sigma f$, there were significant differences between curing mode $(p=0.001)$ and addition of nanotubes $(p=0.0002)$. The interaction was also found to be significant $(p=0.0000)$. For $E$, there were significant differences between curing mode $(p=0.006)$ and addition of nanotubes $(p=0.0000)$. The interaction was also found to be significant $(p=0.0009)$. For Microhardeness, significant differences were observed only for curing mode $(\mathrm{p}=0.001)$.

Adding 0.3\% $\mathrm{TiO}_{2}$-nt (S03) and $0.9 \%$ (S09) increased the of of the cement in the self-curing mode with similar values to the control group in the dual condition (DCT). As for the dualcuring mode, the addition of nanotubes did not increase the value of the $\sigma f$ and the addition of $0.6 \%$ (D06) decreased the value compared to the control (DCT). The average E increased with the addition of $0.9 \%$ for self-curing condition.

The addition of $0.6 \%$ (S06 and D06) and 0.9\% (S09 and D09) of $\mathrm{TiO}_{2}$-nt cement increased microhardness values when compared to the control groups (SCT and DCT). The addition of $0.3 \%$ (S03 and D03) nanotubes resulted in hardness data similar to SCT and DCT and the groups with 0.6 and $0.9 \% \mathrm{TiO}_{2}$-nt.

\subsection{Cell viability}

The addition of $\mathrm{TiO}_{2}$-nt at different concentrations did not affect the cement $\mathrm{pH}$ values (Table 4).
Table 4 - Control and experimental groups and their respective $\mathrm{pH}$ values.

\begin{tabular}{lllllll} 
& \multicolumn{6}{l}{ Groups } \\
\cline { 2 - 7 } & CP & CN & DCT & D03 & D06 & D09 \\
\hline $\mathrm{pH}(p=0,6967)$ & 7.20 & 7.97 & 7.60 & 7.56 & 7.82 & 7.69 \\
\hline
\end{tabular}

The result of the MTT colorimetric assay is shown in Fig. 4. Within 24 h, D03, D06 and D09 had achieved a similar result to that of the CP group. The DCT group had lower absorbance values than $\mathrm{CP}$, which was used as a benchmark, with a statistically significant difference $(p=0.000)$. At $48 \mathrm{~h}$, no groups showed a significant difference compared to the CP group, with the exception of CN. At $72 \mathrm{~h}$, there was a decrease in cell viability. However, the profile was similar to the 48-h-period in that all groups had results similar to those of CP.

Observing the images obtained by optical microscopy at the end of each period (Fig. 5), it was found that within $72 \mathrm{~h}$, the wells were at confluency. Due to the lack of space, cell death occurred, confirming the decrease in viability during this period.

\section{Discussion}

The addition of $\mathrm{TiO}_{2}$ nanostructures to dental polymers has shown promising results [9-11,13]. Overall, positive results were found in the current investigation for a selfadhesive resin cement with $\mathrm{TiO}_{2}$-nt reinforcement, and the

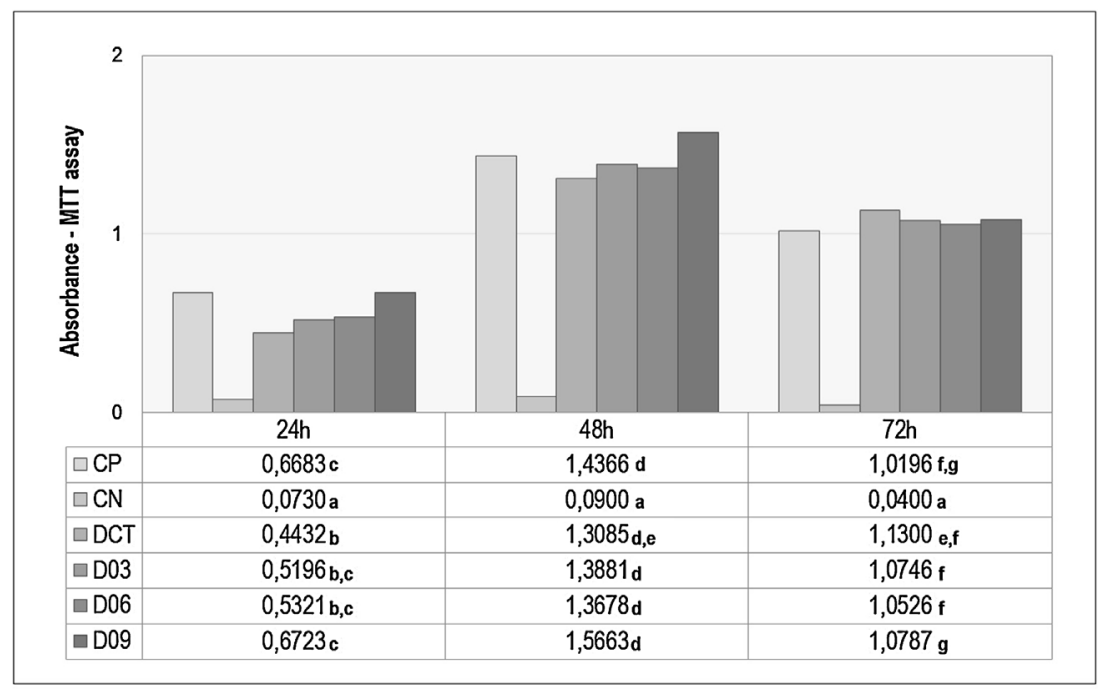

Fig. 4 - MTT reduction colorimetric assay at 24,48 and $72 \mathrm{~h}$. 

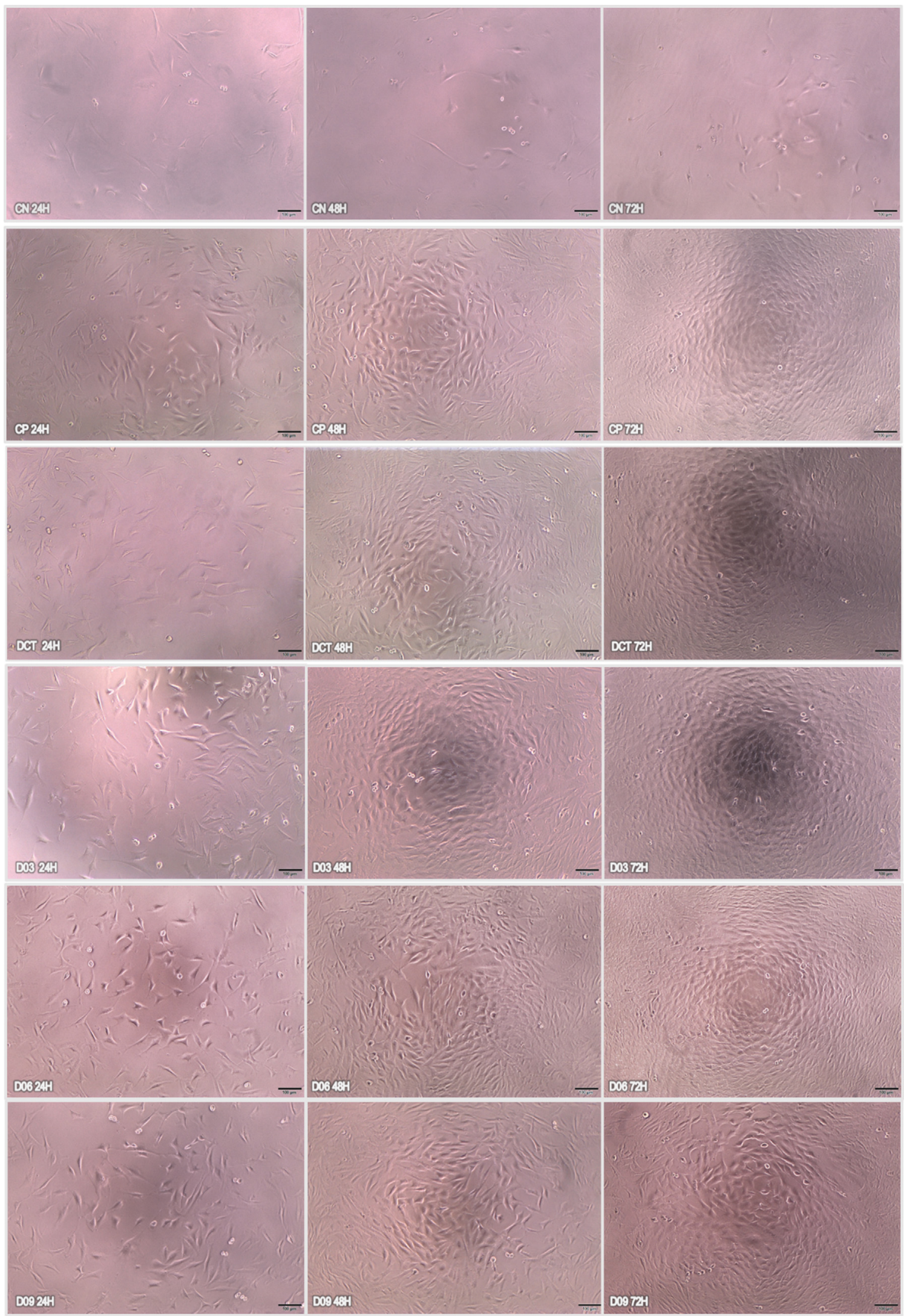

Fig. 5 - Optical microscopy images for 24, 48 and $72 \mathrm{~h}$ (columns) for all groups: CN, CP, DCT, D03, D06 and D09 (lines). 
physical-chemical, mechanical and biological behaviors were improved. These improvements, especially in the self-curing condition, are important for the longevity and clinical performance of this cement.

The dual-curing condition proposed in this study simulates the use of the self-adhesive resin cement in the cementation of indirect restorations containing infrastructures that do not allow the passage of light, such as Y-TZP, in which the cement on the restoration margins receives the curing light after a few minutes of cementation.

The dual-curing protocol performed in this study is based on the one employed by Soares et al. [19] in which the lightactivation was performed 6 min after the handling of the resin cement without impairing its mechanical properties. This delay in light activation has shown to improve properties of resin-based cements [18].

Regardless of the percentage added $(0.3 \%, 0.6 \%$, or $0.9 \%)$, the DC was higher at all time points $(3,6,9,12$, and $15 \mathrm{~min})$ compared to the control for both polymerization modes. The non-reinforced cement did not reach the same DC in SCT when compared to the condition in which it was submitted to light-activation (DCT), which is in agreement with other studies $[6,24,25]$. Thus, the chemical reaction alone of the evaluated dual-cured resin cement without light-activation seems therefore not to be sufficient to achieve reasonable levels of conversion of $\mathrm{C}=\mathrm{C}$ double bonds for polymer formation after 15 min of mixing. The photo-initiator system allows a fast reaction and high conversion when the materials are subjected to light-activation [6].

The addition of $0.3 \%$ to $0.9 \%$ of $\mathrm{TiO}_{2}$-nt in the self-curing mode increased the DC to values close to the ones obtained by the dual-curing condition without $\mathrm{TiO}_{2}$-nt additive (DCT), which would justify the use of $\mathrm{TiO}_{2}$-nt additives in clinical situations that rely exclusively on chemical polymerization such as the cementation of fiber-reinforced posts in root canals. It should be noted that the results of this study demonstrate that the relationship between the addition of $\mathrm{TiO}_{2}$-nt and $\mathrm{DC}$ is not straightforward, which means that the increase of the concentration of $\mathrm{TiO}_{2}$-nt do not necessarily promotes greater DC values. This result can be justified by the fact that the addition of $0.6 \%$ promotes an agglomeration of nanotubes [10] resulting in links attached to other already polymerized monomer and preventing new connections among them [26]. On the other hand, when $0.9 \%$ was added, the reaction might have been so fast that agglomeration of nanotubes may have been smaller and did not affect the link of monomers.

Even with acceptable values of DC in the dual-curing mode, with the addition of $0.3 \% \mathrm{TiO}_{2}$-nt the values increased $16 \%$. Most likely, the insertion of this percentage allowed the cement to stay more reactive to new connections between monomers remaining in equilibrium with the polymer network that was forming. Increasing concentrations (0.6 and $0.9 \%$ ) of $\mathrm{TiO}_{2}$-nt, however, showed an average increase of only $10 \%$, likely due to the rapid increase in viscosity generated by the conversion of the monomers.

The increase of the DC with the addition of $\mathrm{TiO}_{2}$-nt to the cement shows an inducer potential, with the nanotubes possibly acting as a reaction coinitiator and contributing to the increase of strong crosslinked points formed in the polymeric network [10]. This is because at the nanoscale, in particular at $<50 \mathrm{~nm}$, exists a confinement effect of electron pairs that results in an increase of energy between the valence band and the band gap of the material [27]. This energy is expressed chemically as a free radical ( $\mathrm{HO}^{\bullet}$ ) [10] that likely provides additional site links between the monomers.

The addition of $\mathrm{TiO}_{2}$-nt and the polymerization condition did not influence the WS and SL of the self-adhesive resin cement. According to ISO 4049 [21], the value of clinically acceptable WS for polymeric materials is limited to $40 \mu \mathrm{g} / \mathrm{mm}^{3}$ and the SL is less than $7.5 \mu \mathrm{g} / \mathrm{mm}^{3}$. The results found in this study for WS (from 36.19 to $38.47 \mu \mathrm{g} / \mathrm{mm}^{3}$ ) are in accordance with the ISO's recommendations, but SL $\left(7.66-8.14 \mu \mathrm{g} / \mathrm{mm}^{3}\right)$ was above the values stipulated as ideal. This fact was elucidated once the resin-based materials containing acid functional monomers, such as carboxyl groups or phosphate, are significantly more hydrophilic than the materials without functional monomers, which contain only conventional TEGDMA and BIS-GMA $[28,29]$ and are therefore more prone to WS and SL [30]. The amount of inorganic particles [31] and the nature of the bonds between the particles and the organic matrix are important [32] because the diffusion of water between the particles can occur [33]. Furthermore the cement in this study did not react with the calcium of dentin substrate, that promotes additional chemical bond and collaborate with the polymerization process [3], since it accelerates the neutralization of the low $\mathrm{pH}$ of the cement [34].

Some residual unpolymerized monomers may leach into the oral cavity, but most remain trapped in the already polymerized cement [30]. Those that are released into the environment can cause adverse biological reactions, penetrating the dentin tubules and pulp [35]. Those that are stuck in cement reduce the clinical longevity of the material and undergo oxidation and hydrolytic degradation, as evidenced by discoloration of the cementation of the margins [36]. This condition is directly related to the cytotoxicity of the cement, which is another important factor to be analyzed. In the current study, the indirect fibroblast viability was assessed using a MTT and Crystal Violet assay. The results showed that the incorporation of $\mathrm{TiO}_{2}-\mathrm{nt}$ at 24,48 and $72 \mathrm{~h}$ were the same for the CP group, indicating that the addition did not affect cell viability in vitro during these periods for the dual-curing condition. However, the DCT group at $24 \mathrm{~h}$ showed a significant difference in cell viability when compared to CP. This result can be explained by the relationship between the type of polymerization employed and the DC obtained with regard to the cytotoxicity of resin cements [37]. The cements with lower DC showed a significant decrease in cell survival when compared to cements with the highest DC [38].

The of values obtained in this study showed that the presence of $\mathrm{TiO}_{2}$-nt influenced the results. The inclusion of 0.3 and $0.9 \%$ of $\mathrm{TiO}_{2}$-nt increased the $\sigma f$ value in the self-curing condition (S03 and S09) and is similar to the average value of DCT. The linear relationship between the increased amount of inserted nanotubes and an increase in strength was not observed. This may be associated with the higher conversion of monomers to concentrations of $0.3 \%$ and $0.9 \%$ in the same polymerization condition because they are properties which have a direct relationship $[39,40]$. For the dual-curing condition, the inclusion of $0.6 \%$ of $\mathrm{TiO}_{2}$-nt decreased the of value compared to the control (DCT), as already noted for the DC. 
The inclusion of this concentration could have generated the agglomeration of nanometric particles (nanocluster), decreasing the strength of the material. The presence of defects, inclusions or pores has a negative effect on the strength of a material to act as a stress concentrator [41]. The E values obtained for the $\mathrm{TiO}_{2}$-nt-added resin cements cured in selfcuring mode (1.9-6.8 GPa) are numerically smaller then with in the dual-curing mode (4.8-7.9 GPa) [6]. The same result was found for the DCT group compared to SCT. This can occur because the characterization of the $\mathrm{E}$ of the development is based on the changes from an initially viscous cement to a solid material [19]. The addition of $\mathrm{TiO}_{2}$-nt did not change the $\mathrm{E}$ for the dual-curing group, but the addition of $0.9 \%$ in the self-curing group (S09-1.71 GPa) resulted in values similar to those of the dual-curing groups. This increase can be explained by the fact that the $E$ of the material can be changed depending on the inorganic composition [42,43]. It has been suggested that a desirable $\mathrm{E}$ value for a cementing agent should be between the value of the indirect restoration and the mineralized tooth structure (12-14 GPa to dentin and 46-48 GPa enamel [44]), which contributes to reducing stress concentrations at the interface [45] and consequently leads to the reduction of marginal gaps [46].

With the addition of $0.6 \%$ and $0.9 \%$, independent of polymerization conditions, the microhardness results were significantly higher when compared to the control groups. In other studies [10], at a certain concentration, the addition of $\mathrm{TiO}_{2}$-nt leads to a decline in hardness, but discrepancies between methods to evaluate hardness and the material itself are observed. The Knoop indenter is the most suitable for the hardness analysis of polymeric materials [44], and the indenter application site may interfere in the results. This is because in the central region of the specimen, free radicals are dimensionally more exposed compared to located at the ends [47]. Moreover, the high surface area of the hollow nanotube structure allows a resin matrix interlock with the inner and outer surfaces of the tubes, acting to strengthen the structure and resulting in a material with improved mechanical properties [11].

The increase of DC values of the reinforced cement influenced most of the other properties studied, as found in other studies $[37,38,48]$. In a general analysis, the addition of $\mathrm{TiO}_{2}-\mathrm{nt}$ in the evaluated self-adhesive resin cement positively influenced its properties, especially in the self-curing mode, which has an indication for use with certain limitations. There was no consensus on the results as to the optimal concentration to improve all properties evaluated. However, the inclusion of 0.3 wt\% to $0.9 \mathrm{wt} \% \mathrm{TiO}_{2}$-nt was responsible for the most favorable results in the study.

The lack of equality in the results could be improved by the functionalization of nanotubes, one of limitations of this study, once the nanoscale structures tend to agglomerate, decreasing their dispersion into the material [11]. Other limitations as the understanding the real chemical interaction of $\mathrm{TiO}_{2}$-nt and resin monomers and the absence of dentin tissue that have an important role in the neutralizing reaction of self-adhesive resin cement are important factors to be discussed in later studies to allow its feasibility of use in the future.

\section{Conclusions}

The addition of $\mathrm{TiO}_{2}$-nt addition to self-adhesive resin cement had an influence on the DC, flexural strength, elastic modulus, microhardness and indirect fibroblast cell viability. It is possible to considerably increase the DC of the self-adhesive resin cement $15 \mathrm{~min}$ after handling when used in the self-curing condition by adding $0.3 \mathrm{wt} \%$ to $0.9 \mathrm{wt} \%$ of $\mathrm{TiO}_{2}-\mathrm{nt}$.

The mechanical properties of the self-adhesive resin cement ( $\sigma f, \mathrm{E}$ and hardness) were influenced by the presence of $\mathrm{TiO}_{2}$-nt. Indirect cell viability of $\mathrm{TiO}_{2}$-nt-reinforced cement was the same for the CP group and did not result in toxicity among the time tested.

\section{Acknowledgements}

We thank 3M Espe for providing samples of RelyX U200. This paper is in fulfillment of the requirements for the PhD degree in Applied Dental Science for Carla Müller Ramos Tonello, USP, SP, Brazil. This study was supported by a grant from the São Paulo State Research Foundation (FAPESP) (\#2013/10021-5).

\section{REFERE N C E S}

[1] Radovic I, Monticelli F, Goracci C, Vulicevic ZR, Ferrari M. Self-adhesive resin cements: a literature review. J Adhes Dent 2008;10(4):251-8.

[2] De Angelis F, Minnoni A, Vitalone LM, Carluccio F, Vadini M, Paolantonio $\mathrm{M}$, et al. Bond strength evaluation of three self-adhesive luting systems used for cementing composite and porcelain. Oper Dent 2011;36(6):626-34.

[3] De Munck J, Vargas M, Van Landuyt K, Hikita K, Lambrechts $\mathrm{P}$, Van Meerbeek B. Bonding of an auto-adhesive luting material to enamel and dentin. Dent Mater 2004;20(10):963-71.

[4] Vrochari AD, Eliades G, Hellwig E, Wrbas KT. Curing efficiency of four self-etching, self-adhesive resin cements. Dent Mater 2009;25(9):1104-8.

[5] D’Alpino PH, Silva MS, Vismara MV, Di Hipolito V, Miranda Gonzalez AH, de Oliveira Graeff CF. The effect of polymerization mode on monomer conversion, free radical entrapment, and interaction with hydroxyapatite of commercial self-adhesive cements. J Mech Behav Biomed Mater 2015;46:83-92.

[6] Aguiar TR, de Oliveira M, Arrais CA, Ambrosano GM, Rueggeberg F, Giannini M. The effect of photopolymerization on the degree of conversion, polymerization kinetic, biaxial flexure strength, and modulus of self-adhesive resin cements. J Prosthet Dent 2015;113(2):128-34.

[7] Arrais CA, Giannini M, Rueggeberg FA. Kinetic analysis of monomer conversion in auto- and dual-polymerizing modes of commercial resin luting cements. J Prosthet Dent 2009;101(2):128-36.

[8] Komori PC, de Paula AB, Martin AA, Tango RN, Sinhoreti MA, Correr-Sobrinho L. Effect of light energy density on conversion degree and hardness of dual-cured resin cement. Oper Dent 2010;35(1):120-4.

[9] Xia Y, Zhang F, Xie H, Gu N. Nanoparticle-reinforced resin-based dental composites. J Dent 2008;36(6):450-5.

[10] Sun J, Forster AM, Johnson PM, Eidelman N, Quinn G, Schumacher $\mathrm{G}$, et al. Improving performance of dental 
resins by adding titanium dioxide nanoparticles. Dent Mater 2011;27(10):972-82.

[11] Dafar MO, Grol MW, Canham PB, Dixon SJ, Rizkalla AS. Reinforcement of flowable dental composites with titanium dioxide nanotubes. Dent Mater 2016;32(6):817-26.

[12] Poosti M, Ramazanzadeh B, Zebarjad M, Javadzadeh P, Naderinasab M, Shakeri MT. Shear bond strength and antibacterial effects of orthodontic composite containing $\mathrm{TiO}_{2}$ nanoparticles. Eur J Orthod 2013;35(5):676-9.

[13] Elsaka SE, Hamouda IM, Swain MV. Titanium dioxide nanoparticles addition to a conventional glass-ionomer restorative: influence on physical and antibacterial properties. J Dent 2011;39(9):589-98.

[14] Cheng LC, Jiang X, Wang J, Chen C, Liu RS. Nano-bio effects: interaction of nanomaterials with cells. Nanoscale 2013;5(9):3547-69.

[15] Chen X, Mao SS. Titanium dioxide nanomaterials: synthesis, properties, modifications, and applications. Chem Rev 2007;107(7):2891-959.

[16] Roy P, Berger S, Schmuki P. $\mathrm{TiO}_{2}$ nanotubes: synthesis and applications. Angew Chem Int Ed Engl 2011;50(13):2904-39.

[17] Goto K, Tamura J, Shinzato S, Fujibayashi S, Hashimoto M, Kawashita M, et al. Bioactive bone cements containing nano-sized titania particles for use as bone substitutes. Biomaterials 2005;26(33):6496-505.

[18] Furuse AY, Santana LO, Rizzante FA, Ishikiriama SK, Bombonatti JF, Correr GM, et al. Delayed light activation improves color stability of dual-cured resin cements. J Prosthodont 2016, http://dx.doi.org/10.1111/jopr.12509. Epub ahead of print.

[19] Soares CJ, Bicalho AA, Verissimo C, Soares P, Tantbirojn D, Versluis A. Delayed photo-activation effects on mechanical properties of dual cured resin cements and finite element analysis of shrinkage stresses in teeth restored with ceramic inlays. Oper Dent 2016;41(5):491-500.

[20] Arruda LB, Santos CM, Orlandi MO, Schreiner WH, Lisboa-Filho PN. Formation and evolution of $\mathrm{TiO}_{2}$ nanotubes in alkaline synthesis. Ceram Int 2015;41(2):8.

[21] ISO 4049. Dentistry-polymer-based restorative materials. International Organization for Standardization; 2009.

[22] ISO 9917-2. Dentistry-water based cements. International Organization for Standardization; 2010.

[23] ISO 10993-5. Biological evaluation of medical devices. Part 5: tests for in vitro cytotoxicity. International Organization for Standardization; 2009.

[24] Aguiar TR, Di Francescantonio M, Arrais CA, Ambrosano GM, Davanzo C, Giannini M. Influence of curing mode and time on degree of conversion of one conventional and two self-adhesive resin cements. Oper Dent 2010;35(3):295-9.

[25] Di Francescantonio M, Aguiar TR, Arrais CA, Cavalcanti AN, Davanzo CU, Giannini M. Influence of viscosity and curing mode on degree of conversion of dual-cured resin cements. Eur J Dent 2013;7(1):81-5.

[26] Peutzfeldt A. Resin composites in dentistry: the monomer systems. Eur J Oral Sci 1997;105(2):97-116.

[27] Rodrigues JA, Fernández-García M. Synthesis, properties, and applications of oxide nanomaterials. New Jersey: John Wiley \& Sons, Inc.; 2007.

[28] Liu Q, Meng X, Yoshida K, Luo X. Bond degradation behavior of self-adhesive cement and conventional resin cements bonded to silanized ceramic. J Prosthet Dent 2011;105(3):177-84.

[29] Malacarne J, Carvalho RM, de Goes MF, Svizero N, Pashley DH, Tay FR, et al. Water sorption/solubility of dental adhesive resins. Dent Mater 2006;22(10):973-80.
[30] Petropoulou A, Vrochari AD, Hellwig E, Stampf S, Polydorou O. Water sorption and water solubility of self-etching and self-adhesive resin cements. J Prosthet Dent 2015;114(5):674-9.

[31] Toledano M, Osorio R, Osorio E, Fuentes V, Prati C, Garcia-Godoy F. Sorption and solubility of resin-based restorative dental materials. J Dent 2003;31(1):43-50.

[32] Mese A, Burrow MF, Tyas MJ. Sorption and solubility of luting cements in different solutions. Dent Mater J 2008;27(5):702-29.

[33] Kalachandra S. Influence of fillers on the water sorption of composites. Dent Mater 1989;5(4):283-8.

[34] Ferracane JL, Stansbury JW, Burke FJ. Self-adhesive resin cements-chemistry, properties and clinical considerations. J Oral Rehabil 2011;38(4):295-314.

[35] Yiu CKY, King NM, Carrilho MRO, Sauro S, Rueggeberg FA, Prati C, et al. Effect of resin hydrophilicity and temperature on water sorption of dental adhesive resins. Biomaterials 2006;27(9):1695-703.

[36] Tanaka K, Taira M, Shintani H, Wakasa K, Yamaki M. Residual monomers (TEGDMA and Bis-GMA) of a set visible-light-cured dental composite resin when immersed in water. J Oral Rehabil 1991;18(4):353-62.

[37] Monteiro GQM, Souza FB, Pedrosa RF, Sales GCF, Castro $\mathrm{CMMB}$, Fraga SN, et al. In vitro biological response to a self-adhesive resin cement under different curing strategies. J Biomed Mater Res Part B Appl Biomater 2010;92b(2):317-21.

[38] Morgan LF, Teixeira KI, Vasconcellos WA, Albuquerque RC, Cortes ME. Correlation between the cytotoxicity of self-etching resin cements and the degree of conversion. Indian J Dent Res 2015;26(3):284-8.

[39] Goncalves F, Boaro LC, Miyazaki CL, Kawano Y, Braga RR. Influence of polymeric matrix on the physical and chemical properties of experimental composites. Braz Oral Res 2015;29:1-7.

[40] Ferracane JL, Greener EH. The effect of resin formulation on the degree of conversion and mechanical properties of dental restorative resins. J Biomed Mater Res 1986;20(1):121-31.

[41] Callister Jr WD, Rethwisch DG. Materials science and engineering: an introduction. 8th ed. New Jersey, USA: John Wiley and Sons; 2009.

[42] Kim KH, Ong JL, Okuno O. The effect of filler loading and morphology on the mechanical properties of contemporary composites. J Prosthet Dent 2002;87(6):642-9.

[43] Aguiar TR, Di Francescantonio M, Bedran-Russo AK, Giannini M. Inorganic composition and filler particles morphology of conventional and self-adhesive resin cements by SEM/EDX. Microsc Res Tech 2012;75(10):1348-52.

[44] Anusavice KJ. Phillips, materiais dentários. 11th ed. Rio de Janeiro: Elsevier Editora Ltda; 2005

[45] Furuichi T, Takamizawa T, Tsujimoto A, Miyazaki M, Barkmeier WW, Latta MA. Mechanical properties and sliding-impact wear resistance of self-adhesive resin cements. Oper Dent 2016;41(3):E83-92.

[46] Li ZC, White SN. Mechanical properties of dental luting cements. J Prosthet Dent 1999;81(5):597-609.

[47] Hofmann N, Papsthart G, Hugo B, Klaiber B. Comparison of photo-activation versus chemical or dual-curing of resin-based luting cements regarding flexural strength, modulus and surface hardness. J Oral Rehabil 2001;28(11):1022-8.

[48] Pegoraro TA, da Silva NR, Carvalho RM. Cements for use in esthetic dentistry. Dent Clin North Am 2007;51(2):453-71. 